\title{
Globus Pharyngeus
}

\author{
Sumit Sharma* \\ Department of ENT, Mayo Institute of Medical Sciences, India
}

Submission: June 19, 2017; Published: July 10, 2017

*Corresponding author: Sumit Sharma, Department of ENT, Royale Medical Centre, L 3/67, Sector-D, Near Happy World Girls College, Aliganj, Lucknow, 226024, India, Tel: 9839178240; Email: entsumit@rediffmail.com

\section{Editorial}

The term Globus was first described by Purcell in 1707 who coined the term globus hystericus, the word globus originating from the Latin meaning "ball" and "hystericus" reflecting the then assumed psychological component of the disorder [1] Globus is a persistent or intermittent non-painful sensation of a lump or foreign body in the throat. It is a commonly encountered clinical condition that is usually long-lasting, difficult to treat, and has a tendency to recur. It is a common disorder of indeterminate origin and constitutes about 5\% of all new ENT referrals [2] the literature reports a slight female preponderance [3]. The disorder was renamed globus pharyngeus in 1968 [4]. Globus Pharyngeus has more recently been defined as

a. A persistent or intermittent sensation of a lump or foreign body in the throat for at least 12 weeks,

b. Occurrence of the sensation between meals,

c. Absence of dysphagia and odynophagia,

d. Absence of pathological gastroesophageal reflux (GERD), achalasia, or other motility disorder with a recognized pathological basis (e.g., scleroderma of the esophagus) [5].

\section{Natural history of the Disease}

No long term study is yet available hence the natural history of this condition has not been fully studied. In one study that followed 74 globus patients for an average of 7 years and 7 months, $45 \%$ of the patients had persistent symptoms during the follow-up period [6]. No reliable prognostic factor was revealed even after an in-depth analysis of the features at clinical presentation. In another long-term follow-up study, $60 \%$ of the patients had improved or resolved symptoms over a 5-year period and the male patients with a history of globus less than 3 months and who did not complain of any associated throat symptoms were reported to have the greatest chance of becoming asymptomatic or symptomatically improved [7].

Typically, Globus is relieved by ingestion of solids or liquids and tends to be worse on dry swallows. Globus may be associated with throat irritation, soreness, dryness, catarrh, or constant throat clearing. It forms a large part of ENT practice and may account for about $4 \%$ of referrals to our outpatient clinics [1] The prevalence is much higher in the general population as most people may not present to hospital with it. A recent study by Ali and Wilson [4] found that up to $78 \%$ of patients presenting to non-ENT clinics had had Globus-type symptoms.

\section{Potential Causes of Globus}

Most of the time we do not use any scoring system to grade Globus Pharyngeus. The reflux symptom index and the reflux finding score are not particularly valid diagnostic tools when used in globus patients [8]. The Glasgow Edinburgh Throat Score (GETS) has been validated for use in globus but is not widely used [9].

The common causes attributed in the etiology of Globus Pharyngeus could be:

Gastroesophageal Reflux Disease: There is a considerable debate over the involvement of gastroesophageal reflux in the etio-pathogenesis of Globus Pharyngeus. A number of studies are both for and against the fact. Malcomson was the first to link GERD to the globus sensation through the use of barium swallow. Chevalier et al. [10] Looked at globus patients with and without typical GOR symptoms. They found that $66.6 \%$ of the non-reflux globus group and $80 \%$ of the GOR globus group had significant episodes of reflux (based on $\mathrm{pH}$ monitoring). Whereas in direct contrast, Chen et al. in a similar study found no evidence of reflux in globus patients based on ambulatory pH monitoring [11].

Despite this gastroesophageal reflux (GER) has been suggested to be a major etiology of this symptom, potentially accounting for $23 \%-68 \%$ of globus patients [10]. Two basic mechanisms have been proposed to explain the association between GERD and the globus sensation [10]:

a. Direct irritation and inflammation of the laryngopharynx by retrograde flow of gastric contents, also known as laryngopharyngeal reflux (LPR); 
b. Vagovagal reflex hypertonicity of the UES triggered by acidification or distention of the distal esophagus.

c. Reflux is, however, best detected by impedance. Anandasabapathy and Jaffin (11) using multichannel intraluminal impedance and $\mathrm{pH}$ monitoring (MII-pH) have suggested that globus may also be due to nonacid (NAR) reflux. As MII-pH can detect reflux episodes independent of acid changes, it is allegedly more accurate at picking up proximal reflux. This latter study found NAR and proximal reflux to be significant predictors of globus.

Factors favoring the involvement of GORD in etiopathogenesis of Globus Pharyngeus include

a) Significant episodes of reflux based on $\mathrm{pH}$ monitoring studies.

b) Globus symptom score was significantly higher in patients with GERD than in those without.

c) Globus sensation improved after 8 wks of proton pump inhibitor (PPI) therapy.

d) Several population-based surveys have supported such a potential link between GERD and the globus symptom by demonstrating an increased risk of globus among patients with GERD symptoms.

e) Endoscopic evaluation also reveals a congested post cricoid area and posterior laryngitis in patients of Globus Pharyngeus. Although not always.

Psychological Factors and Stress: Globus Pharyngeus has traditionally been associated with Psychological problems either as causative factor or triggering factor. The association was initially thought to be so strong that the disease wads earlier known as Globus Hystericus. Many of these patients are suffering from cancer phobias because someone close developed a cancer in the near past and hence they develop this phobia, this is also the primary reason for investigating these patients only to rule out malignancy, however even after investigations many of these (44\% after 5 years of follow up - [11,12] were symptomatic on long term followup. It is the fourth most discriminating symptom of a somatization disorder after vomiting, aphonia, and painful extremities [11]. Personality studies have found higher levels of alexithymia, neuroticism, and psychological distress (including anxiety, low mood, and somatic concerns) and lower levels of extraversion in patients presenting with globus [10].

Many patients report stressful life events preceding symptom onset, suggesting that life stress might be a cofactor in symptom of the condition and in exacerbation. Indeed, up to $96 \%$ of patients with globus report symptom exacerbation during periods of high emotional intensity [10]. There is also a correlation between psychological factors and globus pharyngeus patients of the two types - one with Gastroesophageal reflux positive and the other with a negative Gastroesophageal reflux. Globus patients with
LPR exhibited weaker psychological symptoms than non-LPR globus patients, and globus patients who did not respond to PPI had significantly higher anxiety scores [10]. Although etiological role of psychological factors have not yet been established but these factors must always be kept in mind while evaluating these patients.

Abnormal Upper Esophageal Sphincter Function: Contradictory studies are available for the role of USE function in the etiology of Globus pharyngeus. Some studies suggest that abnormal UES function has to be a cause of globus sensation. Elevated UES pressure has been found to be much more frequent in patients with globus sensation than in controls $(28 \%$ vs. $3 \%$ ), suggesting that hypertensive UES is a background factor for globus [10]. Additionally, injection of botulinum toxin into the cricopharyngeal muscle in a patient with both globus and extremely high UES pressure led to a resolution of the globus symptom and a decrease in UES pressure [10].

In a study conducted by Cook IJ [13] they examined the psychological profile and effect of acute mental stress (dichotic listening task) on UES tone in patients reporting to the clinic with globus sensation and concluded that in patients with a history of globus sensation, resting UES pressure and its response to stress is normal. They also suggested that UES hyper responsiveness to other stimuli or subjective intolerance to changes in UES pressure could account for symptoms of globus sensation. Tokashiki et al. [13], however, showed that perfusion of $\mathrm{HCl}$ into the distal esophagus was related to a sensation of globus associated with a rise in UOS pressure. This rise in pressure was independent of the detection of a rise in $\mathrm{pH}$ in the hypo pharynx. S. Kortequee et al. [11] found that videofluoroscopic evidence of pharyngeal dysfunction especially laryngeal penetration had a strong association with globus.

\section{Other Causes of Globus Pharyngeus}

I. Pharyngeal inflammatory causes.

II. Cervical Osteophytes.

III. Esophageal motor disorders.

IV. Hypertrophy of the tongue base.

V. Upper aerodigestive tract malignancy.

VI. Retroverted epiglottis.

VII. Thyroid diseases.

VIII. Cervical heterotopic gastric mucosa.

IX. Rare tumors.

X. Others. Temporo mandibular joint disorders, hyper viscosity of the nasopharyngeal mucosa, Eagle's syndrome, excessive laryngeal and pharyngeal tension, and salivary hypo function [10]. 


\section{Conclusion}

Globus Pharyngeus is a pharyngeal disorder of unknown etiology, the diagnosis of which is clinical. So far there are no studies that show that these patients eventually develop pharyngeal malignancy. A number of studies demonstrate that rigid endoscopy and barium swallow add little valuable information in evaluating these patients and investigations are done to rule out malignancy and patient satisfaction but unnecessary investigations must not be done, because of this reason there is no standard protocol for its diagnosis and management.

A number of studies suggest that GERD is a major cause of globus, though this remains under considerable debate. A number of other disorders like such as abnormal UES function, esophageal motility disorders, structural head and neck diseases, and psychological factors, have been suggested as potential causes of globus but none have been proved as the etiological factor. A complete head and neck examination including fibreoptic laryngoscopy can be done if patient's symptoms are not relieved with routine management. It's advisable that over investigating these patients can often add unnecessary stress to a group of these patients who already seem to have higher levels of depression, anxiety, and other somatic concerns. If the standard PPI therapy fails to relieve symptoms then other treatment modalities like speech therapy, anti-depressants, and cognitive-behavioral therapy, should be considered. A welldesigned, randomized controlled study is required to establish the cause of the disease.

\section{References}

1. PJ Moloy, R Charter (1982) The globus symptom. Incidence, therapeutic response, and age and sex relationships. Archives of Otolaryngology 108(11): 740-744.
2. WG Thompson, KW Heaton (1982) Heartburn and globus in apparently healthy people. Canadian Medical Association Journal 126(1): 46-48.

3. J Purcell (1707) A Treatise of Vapours or Hysterick Fits, (2 ${ }^{\text {nd }}$ edn), Edward Place, London, UK.

4. KG Malcomson (1968) Globus hystericus vel pharyngis (a recommaissance of proximal vagal modalities). Journal of Laryngology and Otology 82(3): 219-230.

5. JP Galmiche, RE Clouse, A Bálint (2006) Functional esophageal disorders. Gastroenterology 130(5): 1459-1465.

6. Rowley H, O’Dwyer TP, Jones AS, Timon CI (1995) The natural history of globus pharyngeus. Laryngoscope. 105: 1118-1121.

7. Timon C, O' Dwyer T, Cagney D, Walsh M (1991) Globus pharyngeus: long-term follow-up and prognostic factors. Ann Otol Rhinol Laryngol 100: $351-354$

8. F Millichap, M Lee, T Pring (2005) A lump in the throat: should speech and language therapists treat globus pharyngeus? Disability and Rehabilitation 27(3): 130.

9. KHM Ali, JA Wilson (2007) What is the severity of globus sensation in individuals who have never sought health care for it? Journal of Laryngology and Otology 121(9): 865-868.

10. Bong Eun Lee and Gwang Ha Kim Globus pharyngeus: A review of its etiology, diagnosis and treatment. World J Gastroenterol 18(20): 24622471.

11. S Kortequee, PD Karkos, H Atkinson, N Sethi, DC Sylvester, et al. (2013) Management of Globus Pharyngeus. International Journal of Otolaryngology 2013: 5.

12. EC Cashman, MJ Donnelly (2010) The Natural History of Globus Pharyngeus. International Journal of Otolaryngology 2010: 4.

13. Cook IJ, Dent J, Collins SM (1939) Upper esophageal sphincter tone and reactivity to stress in patients with a history of globus sensation. Dig Dis Sci 34(5): 672-676.
This work is licensed under Creative Commons Attribution 4.0 License DOI: $10.19080 /$ GJO.2017.08.555746
Your next submission with Juniper Publishers will reach you the below assets

- Quality Editorial service

- Swift Peer Review

- Reprints availability

- E-prints Service

- Manuscript Podcast for convenient understanding

- Global attainment for your research

- Manuscript accessibility in different formats ( Pdf, E-pub, Full Text, Audio)

- Unceasing customer service

Track the below URL for one-step submission https://juniperpublishers.com/online-submission.php 